\title{
Fahr's Disease With Intracerebral Hemorrhage at the Uncommon Location: A Case Report
}

\author{
Baek Hee Jang, MD, Seong Wook Son, MD, Chung Reen Kim, MD
}

Department of Physical Medicine and Rehabilitation, Ulsan University Hospital, Ulsan, Korea

\begin{abstract}
Fahr's disease (FD) is a rare neurologic disorder characterized by the symmetric and bilateral intracerebral calcification in a patient. We describe the case of a 65 -year-old woman who presented with gait disturbance, abnormal mentality, and visual field defect. The result of a brain computerized tomography showed spontaneous intracranial hemorrhage in the right parieto-occipital area, and also showed the incidence of symmetric and bilateral intracerebral calcification. Moreover, laboratory studies indicated characteristic hypoparathyroidism. This brings us to understand that additionally, one of her sons also presented with similar intracerebral calcification, and was subsequently diagnosed with FD. Thus, her case was consistent with that of a patient experiencing FD. The patient had hypertension, which we now know might have caused the intracerebral hemorrhage. However, this patient's brain lesions were in uncommon locations for spontaneous intracerebral hemorrhage, and the lesions were noted as occurring away from the identified heavily calcified areas. Thus, it seemed that the massive calcification of cerebral vessels in the basal ganglia, the most common site of intracerebral hemorrhage, might have prevented a hypertensive intracerebral hemorrhage. Eventually, an intracerebral hemorrhage occurred in an uncommon location in the patient's brain.
\end{abstract}

Keywords Idiopathic basal ganglia calcification 1, Intracranial hemorrhages

\section{INTRODUCTION}

Fahr's disease (FD) is a neurologic disorder which is characterized with abnormal calcium deposits in the bilateral basal ganglia, and in other subcortical structures of the brain. It was first described by Karl Theodor Fahr [1] in 1930. To begin with, FD is characterized by symmetrical intracranial calcification, hypoparathyroidism, and neurological manifestations in the brain [2]. The typical presentation usually starts between 40 and 60 years of age, with a progressive cognitive decline and psychiatric abnormalities, or movement disorders like extrapyramidal symptoms and dyskinesia [3]. Rarely is it that case that cerebrovascular accidents were also observed in patients diagnosed with FD. Previously, an aneurysmal subarachnoid hemorrhage and intracranial hemorrhage

Received July 27, 2018; Accepted September 13, 2018

Corresponding author: Chung Reen Kim

Department of Physical Medicine and Rehabilitation, Ulsan University Hospital, 877 Bangeojinsunhwan-doro, Dong-gu, Ulsan 44033, Korea. Tel: +8252-250-8730, Fax: +82-52-250-7211, E-mail: crkim@uuh.ulsan.kr

ORCID: Baek Hee Jang (http://orcid.org/0000-0002-1350-5281); Seong Wook Son (http://orcid.org/0000-0002-9657-5401); Chung Reen Kim (http:// orcid.org/0000-0002-0528-6189).

(c) This is an open-access article distributed under the terms of the Creative Commons Attribution Non-Commercial License (http://creativecommons.org/ licenses/by-nc/4.0) which permits unrestricted noncommercial use, distribution, and reproduction in any medium, provided the original work is properly cited. Copyright (C) 2019 by Korean Academy of Rehabilitation Medicine 
(ICH) at the right thalamus and midbrain in FD were reported in some cases [4-6]. However, here we describe a case of FD that presented with ICH in the right parietooccipital lobe, and as it is interestingly noted, the lesion was in an unusual location for spontaneous ICH.

\section{CASE REPORT}

A 65-year-old female was admitted to the rehabilitation unit with the complaint of a cognitive deficit and a gait disturbance. During the past year, she developed a progressively worsening deterioration of the usual mental and motor functions. The patient noted that the characteristic memory loss progressed slowly; thus, recently she felt difficulty in recalling current events. At that time, the gait disturbance had also gradually progressed and worsened. Then, 2 months earlier, it is noted that a spontaneous ICH occurred in the right cerebral hemisphere, and the removal procedure for hematoma was performed immediately. After the procedure, it was noted that the ICH improved, but the visual field disturbance remained. According to the patient's past medical history, she was also diagnosed with hypertension 5 years ago, and was taking hypertension drugs to manage those conditions associated with the HTN diagnosis.

At the time of admission, the patient was awake and alert, but was notably disoriented. The score of her MiniMental State Examination on admission was recorded at $18 / 30$. Additionally, the Korean version of the Geriatric Depression Scale also indicated that the patient suffered from an episode of severe depression. The patient's neurologic examination showed a reduced visual field. The
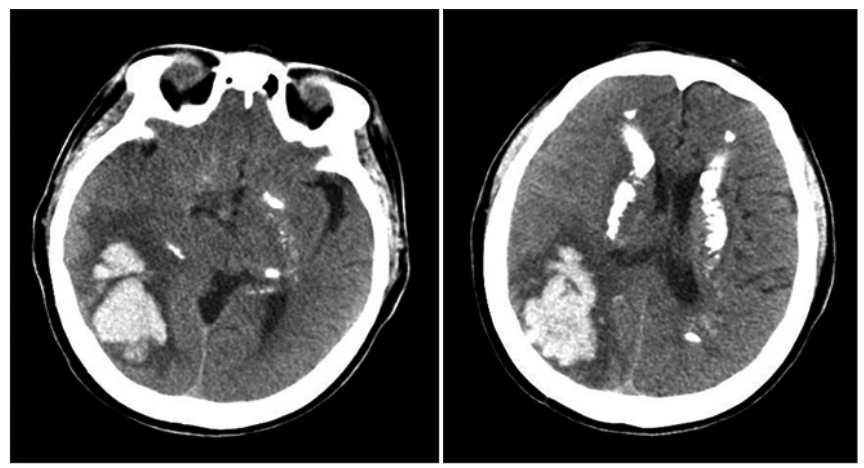

Fig. 1. Computed tomography scan of the patient's brain shows an intracerebral hemorrhage in the right parietooccipital area, with calcification of bilateral periventricular white matter, thalamus, and cerebellum. patient's noted motor power was recorded at $5 / 5$ at both the upper and lower extremities, but she walked with a reduced speed, step length, and reduced arm swing, which was comparable with the Parkinsonian gait. She also had an expressionless face and a noted decreased voice volume. The results of the brain computerized tomography (CT) showed ICH in the right parietal and occipital lobes, and a broad calcification of the bilateral periventricular white matter, thalamus, and cerebellum (Fig. 1). The patient's hematological examination yielded a normal complete blood count. In addition, she had a normal blood glucose level, renal function, and liver enzymes. However, a review of the patient's serum calcium and ionized calcium level were recorded at $6.6 \mathrm{mg} / \mathrm{dL}$ (normal level, 8.5-10.5 mg/dL) and $0.66 \mathrm{mmol} / \mathrm{L}$ (normal level, $1.05-1.32 \mathrm{mmol} / \mathrm{L}$ ), respectively. In this case, the serum parathyroid hormone level was $7.61 \mathrm{pg} / \mathrm{mL}$ (normal level, 15-65 pg/mL). However, her thyroid-stimulating hormone level was $2.23 \mu \mathrm{IU} / \mathrm{L}$ (normal, 0.4-4.0 $\mu \mathrm{IU} /$ $\mathrm{L}$ ) and T3 and free T4 level were $96.5 \mathrm{ng} / \mathrm{dL}$ (normal level, 61-173 ng/dL) and $1.29 \mathrm{ng} / \mathrm{dL}$ (normal level, 0.8-1.9 ng/ $\mathrm{dL})$, respectively. Therefore, the laboratory studies indicated that the patient suffered from hypocalcemia and hypoparathyroidism.

The patient had two sons. Her 38-year-old younger son was already diagnosed with FD 4 years ago. His CT scan also showed broad bilateral basal ganglia, thalamus and cerebellar calcification (Fig. 2). However, her elder son upon medical review has not yet shown any neurologic abnormality, nor have any of her other relatives. She was treated with a course of olmesartan medoxomil (Olmetec; Merck Canada Inc., Quebeck, Canada) 20 mg per day for hypertension. Calcitriol (Rocaltrol; Roche, Basel, Switzer-
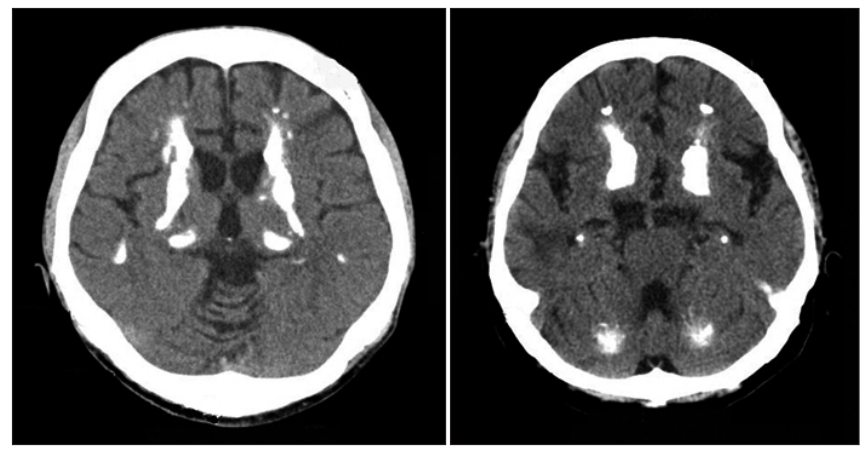

Fig. 2. Computed tomography scan of the younger son's brain shows a bilateral basal ganglia, thalamus and cerebellar calcification. 
land) $0.25 \mu$ g and cholecalciferol (Healthcal; Donghwa Pharm Co. Ltd., Seoul, Korea) 500 mg, twice a day, were prescribed for managing the patient's hypoparathyroidism. In addition, physiotherapy was performed for gait disturbance and cognitive therapy for cognitive dysfunction.

Written informed consents were obtained.

\section{DISDUSSION}

There can be many marked causes and comorbidities of Idiopathic FD including: metabolic disease, hypoparathyroidism, and infectious disease, etc. [4,7]. To date, the FD seen in the above example has been rarely reported. The disease is believed to have an autosomal dominant inheritance, but a few cases have been reported to have had an autosomal recessive inheritance [8]. Investigations to find the related genetic locus are still ongoing in this situation. In this case, symptoms were not detected in other siblings, and therefore, whether it was a dominant or recessive gene trait is not clear.

On histopathological study of FD, calcium deposits can be seen in the walls of the intracerebral vessels that may have resulted from the ongoing inflammatory processes [9]. In this case, it might seem to frequently cause acute cerebrovascular accidents, such as with ICH or cerebral infarction; however, among the various reported cases, only a few were associated with these types of cerebrovascular accidents. The Al-Jehani et al. [5] study reported a case with an aneurysmal subarachnoid hemorrhage, which was a right posterior communicating artery aneurysm. The study of Swami and Kar [4] also reported a case of ICH in the right thalamus and midbrain with hypertension and pseudo-hypoparathyroidism. Recently the study of Sgulo et al. [6] also reported two cases of basal ganglia ICH, and a ruptured aneurysm of the pericallosal artery in FD.

Hypertension is the most important risk factor of spontaneous ICH. Studies show that the basal ganglia (55\%) is the commonest site of bleeding followed by the thalamus (26\%), cerebral hemispheres (11\%), brain stem (8\%), and the cerebellum (7\%) [10]. The patient in this case had been diagnosed with hypertension several years ago, which is thought to be the primary cause of the incidence of ICH. However, the location of the ICH in this case was quite peculiar, in that it was found in the right parietal and occipital lobes. Although calcification was found in the affected area, it was identified as remote from the basal ganglia or thalamus where calcification was more notable. Although there have been several reports about FD, only a few reports presented ICH in FD, which indicates that calcification by itself does not increase the risk of ICH, despite the incidence of a broad basal ganglia calcification. Conversely, calcification may prevent ICH by strengthening the tissues or vessels. Considering that the previously reported ICH case also occurred in the midbrain, as well as in the thalamus, the effects of hypertension appear to be greater when calcification has not progressed further. Also, the rare case reports of ICH among FD seemed to be another supportive evidence for the necessity to develop strategies which can be used for the preventing of effects of the calcification. However, because of lack of related studies, it is still too early to conclude the relationships as seen between the incidence of vascular calcification and a decreased hemorrhagic risk. Thus, more histopathologic studies about intracranial calcification may be necessary in the future.

In conclusion, this case was an interesting case of FD with ICH at the uncommon location. It is peculiar that the area affected by ICH had a noted and identified relatively light calcification, and that it is not where spontaneous ICH is usually suspected. Nevertheless, considering that reported cases are relatively rare, further research on the potential association between ICH and intracranial calcification is needed.

\section{CONFLICT OF INTEREST}

No potential conflict of interest relevant to this article was reported.

\section{AUTHOR CONTRIBUTION}

Conceptualization: Kim CR. Methodology: Kim CR. Project administration: Kim CR. Visualization: Jang BH, Son SW. Writing - original draft: Son SW, Jang BH. Writing - review and editing: Kim CR, Jang BH. Approval of final manuscript: all authors.

\section{REFERENCES}

1. Fahr KT. Idiopathische verkalkung der hirngefasse. 
Zentralbl Allg Pathol 1930;50:129-33.

2. Manyam BV. What is and what is not 'Fahr's disease'. Parkinsonism Relat Disord 2005;11:73-80.

3. Wszolek ZK, Baba Y, Mackenzie IR, Uitti RJ, Strongosky AJ, Broderick DF, et al. Autosomal dominant dystoniaplus with cerebral calcifications. Neurology 2006;67: 620-5.

4. Swami A, Kar G. Intracranial hemorrhage revealing pseudohypoparathyroidism as a cause of fahr syndrome. Case Rep Neurol Med 2011;2011:407567.

5. Al-Jehani H, Ajlan A, Sinclair D. Fahr's disease presenting with aneurysmal subarachnoid hemorrhage. J Clin Imaging Sci 2012;2:27.

6. Sgulo FG, di Nuzzo G, de Notaris M, Seneca V, Catapano G. Cerebrovascular disorders and Fahr's disease: report of two cases and literature review. J Clin Neurosci 2018;50:163-4.

7. Baba Y, Broderick DF, Uitti RJ, Hutton ML, Wszolek ZK. Heredofamilial brain calcinosis syndrome. Mayo Clin Proc 2005;80:641-51.

8. Saleem S, Aslam HM, Anwar M, Anwar S, Saleem M, Saleem A, et al. Fahr's syndrome: literature review of current evidence. Orphanet J Rare Dis 2013;8:156.

9. Chalkias SM, Magnaldi S, Cova MA, Longo R, PozziMucelli RS. Fahr disease: significance and predictive value of CT and MR findings. Eur Radiol 1992;2:570-5.

10. Zafar A, Khan FS. Clinical and radiological features of intracerebral haemorrhage in hypertensive patients. J Pak Med Assoc 2008;58:356-8. 